\title{
Lisímetros de DRENAGEM COMO MÉTOdo DE AVALIAÇÃo DE CONTAMINAÇÃo do SOLO E ÁGUA
}

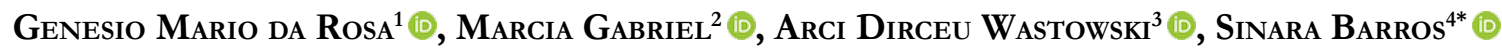

$1 \mathrm{Eng}^{\circ}$ Agr $^{\circ}$ Dr. Prof. Associado Coordenador do Programa de pós-graduação em Ciência e Tecnologia Ambiental- PPGCTA. Linha 7 de Setembro, BR386 $\mathrm{Km} 40 n^{\circ} \mathrm{S} / \mathrm{N}$. Frederico Westphalen - RS. CEP: 98400-000-UFSM.

2 Doutoranda do curso de Pós-Graduação em Agronomia da Universidade Federal de Santa Maria. Av. Roraima no 1000, Cidade Universitária, Bairro Camobi, Santa Maria - RS, CEP: 97105-900.

3 Professor Associado III da Universidade Federal de Santa Maria, campus de Frederico Westphalen - RS. Professor Titular do Programa de Pós-graduação em Ciência e Tecnologia Ambiental - PPGCTA. Linha 7 de Setembro, BR386 Km 40 n S/N. Frederico Westphalen - RS. CEP: $98400-000$.

4 Graduanda do curso de agronomia pela Universidade Federal de Santa Maria, campus de Frederico Westphalen. Linha 7 de Setembro, BR386 Km $40 n^{\circ}$ S/N. Frederico Westphalen - RS. CEP: 98400-000.

* Autorpara correspondência: sinarabarros@yahoo.com.br

Recebido em 17 de agosto de 2019. Aceito em 30 de junho de 2020. Publicado em 31 de julho de 2020.

Resumo - O uso do solo para as atividades agrícolas, pecuária e industrial, possui como consequência elevados níveis de contaminação, em decorrência de descargas acidentais ou voluntárias de poluentes no solo, em águas superficiais e sub superficiais. Por isso, a determinação do impacto do uso de fertilizantes (orgânicos e minerais) no sistema solo-água é de fundamental importância. Nesse sentido, este estudo visa avaliar o uso de lisímetros de drenagem como alternativa para avaliação do impacto de contaminantes no solo e água permitindo uma visão mais aproximada da realidade, sem causar impacto na relação solo-água e que ainda, propiciem avaliação de longo período, permitindo a obtenção de séries históricas do uso de dejetos, efluentes e produtos químicos em áreas cultivadas. Os lisímetros de drenagem, por propiciarem um ambiente controlado, se mostraram eficazes para os estudos dos impactos dos efluentes e adições químicas ao solo e seu reflexo nas águas lixiviadas, tendo como vantagens, o manuseio seguro desses efluentes, além de evitar contaminações desnecessárias em ambientes de pesquisa. A técnica utilizada pode ser destinada para avaliação de outros tipos de efluentes, sendo necessário para isso o correto descarte do solo e da água lixiviada, quando usados contaminantes que impeçam sua reutilização.

Palavras-Chave: Nitrogênio; Dejetos de suínos; Cama de aves; Adubação orgânica; Lisímetro de drenagem.

LOS LISIMETROS DE DRENAJE COMO MÉTODO PARA LA EVALUACION DE LA CONTAMINACION DE SUELO Y AGUA

REsumen - El uso del suelo para actividades agrícolas, ganaderas e industriales produce altos niveles de contaminación, debido a descargas accidentales o voluntarias de contaminantes en el suelo, en aguas superficiales y subterráneas. Por lo tanto, determinar el impacto del uso de fertilizantes (orgánicos y minerales) en el sistema suelo-agua es de fundamental importancia. En este sentido, este estudio tiene como objetivo evaluar el uso de lisímetros de drenaje como una alternativa para evaluar el impacto de los contaminantes en el suelo y el agua, lo que permite una mirada más cercana a la realidad, sin causar un impacto en la relación suelo-agua y que también proporciona una evaluación a largo plazo, lo que permite obtener series históricas del uso de residuos, efluentes y productos químicos en áreas cultivadas. Los lisímetros de drenaje, ya que proporcionan un ambiente controlado, han demostrado ser efectivos para los estudios de los impactos de los efluentes y las adiciones químicas al suelo y su reflejo en las aguas de lixiviados, con las ventajas de un manejo seguro de estos efluentes, además de evitar la contaminación innecesaria en los ambientes de investigación. La técnica utilizada puede usarse para evaluar otros tipos de efluentes, que requieren la eliminación correcta del suelo y el agua de lixiviado, cuando se usan contaminantes que impiden su reutilización.

Palabras Clave: Nitrógeno, Estiércol de porcino; Cama de aves; Fertilización orgánica; Lisímetro de drenaje. 


\section{Drainage Lysimeters as A METHOD OF EVALUATING SOIL AND WATER CONTAMINATION}

Aвstract - The use of soil for agricultural, livestock and industrial activities results in high levels of contamination, due to accidental or voluntary discharges of pollutants into the soil, in surface and sub-surface waters. Therefore, determining the impact of the use of fertilizers (organic and mineral) on the soil-water system is of fundamental importance. In this sense, this study aims to evaluate the use of drainage lysimeters as an alternative to assess the impact of contaminants on soil and water, allowing a closer look at reality, without causing an impact on the soil-water relationship, and which also provide long-term evaluation period, allowing the obtainment of historical series of the use of waste, effluents and chemical products in cultivated areas. Drainage lysimeters, as they provide a controlled environment, have proven effective for studies of the impacts of effluents and chemical additions to the soil and their reflection in leachate waters, with the advantages of safe handling of these effluents, in addition to avoiding unnecessary contamination in environments of research. The technique used can be used to evaluate other types of effluents, requiring the correct disposal of soil and leached water, when contaminants are used that prevent their reuse.

KEYwORDs: Nitrogen; Swine manure; Poultry litter; Organic fertilization; Drainage lysimeters.

\section{INTRODUÇÃO}

As regiões Noroeste e Norte do estado do Rio Grande do Sul são caracterizadas por apresentar pequenas propriedades, onde a suinocultura, a bovinocultura de leite e a avicultura são as principais atividades econômicas desenvolvidas. Entretanto, essas atividades são as principais responsáveis pela geração de elevada quantidade de dejetos, entre eles, os dejetos de suínos que devem ser armazenados em poços de decantação e posteriormente podem ser lançados ao solo, em áreas de cultivo, como forma de adubação orgânica (De Mera et al. 2011). No entanto, essa prática tem contribuído para a contaminação do solo, mananciais superficiais e também lençol freático, quando da não observância da quantidade de dejetos a serem aplicados e a composição dos mesmos (Rosa et al. 2018).

A determinação do impacto do uso de fertilizantes, tanto orgânico como mineral, no sistema solo-água é de fundamental importância. No entanto, a maioria dos experimentos que tentam avaliar esse impacto, são realizados em campo ou em vasos de pouco volume, ou seja, potencialmente poluidores ou pouco representativos, respectivamente. Nesse sentido, é necessário o uso de técnicas que permitam uma visão mais aproximada da realidade, sem causar impacto na relação solo-água e que propiciem avaliação de longo período, permitindo a obtenção de série históricas do uso desses dejetos, em uma mesma área cultivada. Neste sentido, o uso de lisímetros de drenagem é uma alternativa a ser explorada.

Tradicionalmente os lisímetros, em especial os lisímetros de drenagem, tem sido utilizados com o objetivo de avaliar as perdas ocasionadas pela deficiência ou excesso de água nas culturas, além disso, vários estudos têm sido realizados para quantificar as relações entre água, solo, planta e atmosfera (Rosa et al. 2018). No entanto, há carência de instrumentos em campo que quantifiquem a contaminação das águas por nitrato $\left(\mathrm{NO}_{3}^{-}\right)$, elemento que, frequentemente, é oriundo do uso de fertilizantes orgânico e mineral, visto que as áreas agricultáveis possuem diferentes graus de exploração e potencias de poluição do lençol freático, dependendo dentre outros fatores, das práticas agrícolas adotadas em cada região (Carvalho e Zabot 2012).

A utilização de quantidades elevadas de nitrogênio $(\mathrm{N})$, além da capacidade de absorção pelas plantas e/ou sua fixação no solo para posterior utilização das culturas subsequentes pode, segundo Oliveira (2004), causar contaminação no meio ambiente através da lixiviação do nitrato. Além disso, a aplicação de fertilizantes químicos e orgânicos (dejetos de animais) que excedem a demanda das culturas pode resultar em teores elevados de elementos químicos no solo, como o cobre (Cu) e zinco (Zn) (Hong et al. 2007). Segundo Basso et al. (2012), 
adições frequentes de dejeto de suínos com altas concentrações de $\mathrm{Cu}$ e $\mathrm{Zn}$ podem aumentar a quantidade das formas solúveis e trocáveis no solo, potencializando, o acúmulo destes nutrientes, a toxidez às plantas e sua transferência via sedimentos para mananciais de águas superficiais.

Neste contexto, o objetivo deste trabalho foi avaliar uma metodologia para a implantação de lisímetros de drenagem a fim de avaliar a contaminação da água lixiviada, por compostos nitrogenados, com a utilização de diferentes fontes de $\mathrm{N}$ (cama de aves, dejeto de suínos e nitrogênio mineral - ureia) e a contaminação do solo por cobre e zinco, com a utilização das mesmas fontes de adubação orgânica e mineral.

\section{Material e MÉtodos}

A área experimental foi instalada, na Universidade Federal de Santa Maria (UFSM), campus de Frederico Westphalen, no estado do Rio Grande do Sul, com coordenadas geográficas: latitude $27^{\circ} 25^{\prime}$ 43, S, longitude $53^{\circ} 43^{\prime} 25 \mathrm{~W}$, e altitude média de $488 \mathrm{~m}$. O solo da região é classificado como Latossolo Vermelho distroférrico (Streck et al. 2008) e manejado no sistema plantio direto há mais de cinco anos.

O processo de instalação do conjunto de 12 lisímetros e dois poços de observação, iniciou-se com a escolha do local, onde foram observados os fatores de radiação solar incidente, representatividade da área da região, direção dos ventos predominantes e disponibilidade hídrica.

O local da instalação dos lisímetros foi delimitado, sendo uma área de 10 x $20 \mathrm{~m}$. A locação foi iniciada realizando-se o alinhamento no sentido Leste-Oeste, onde foram distribuídas três colunas de 1,4 m espaçadas de 1 metro. As fileiras foram marcadas sendo estas de 1,50 m com espaçamento de 1,40 m entre a primeira e a segunda fileira, de 1,00 m entre a segunda e a terceira, e de 1,40 entre a terceira e a quarta. Entre a primeira e a segunda fileira e a terceira e a quarta fileira foram locados os poços de observação.

Após a locação, iniciou-se a escavação das valas com aproximadamente 1,2 m metros de profundidade onde, após o nivelamento do fundo, foi depositada uma camada de aproximadamente $0,1 \mathrm{~m}$ de areia, com a finalidade de facilitar a acomodação dos lisímetros.

Os lisímetros são caixas fabricadas em fibra de vidro com dimensões de 1,40 x 0,95 m e profundidade de $1,00 \mathrm{~m}$, sendo que as bordas foram reforçadas por abas de $0,05 \mathrm{~m}$ de largura e $0,01 \mathrm{~m}$ de espessura. Os lisímetros receberam furação de $25 \mathrm{~mm}$ na parte inferior dos mesmos, onde foi conectado um flange de PVC rígido, e nesse foi colada uma curva de $90^{\circ}$.

Após essa operação, os lisímetros foram assentados nas valas já preparadas, sendo que no centro das mesmas foram escavadas valas menores e depositados canos de PVC, os quais foram conectados na sequência das curvas de $90^{\circ}$, já instaladas nos lisímetros. Esses canos foram distribuídos nas valas e conectados aos poços de observação. Dessa forma, cada lisímetro foi ligado, por canos, ao poço de observação e na extremidade de cada cano foi acoplada uma torneira para o controle de drenagem da água do solo. Dos lisímetros até os poços foi observada uma inclinação mínima de 2\% para os canos de drenagem, para que a água drenada pudesse chegar ao poço de observação. Os lisímetros foram numerados de 1 a 12, sendo que os primeiros seis foram ligados ao poço um e os demais $\left(7^{\circ}\right.$ ao $\left.12^{\circ}\right)$ ligados ao poço dois. Na Figura 1 é apresentada a sequência do procedimento de instalação dos lisímetros. 
Figura 1. Vista parcial do conjunto de lisímetros de drenagem. A) Colocação do solo nos lisímetros, B) poço de observação e C) Vista final após os procedimentos de instalação.
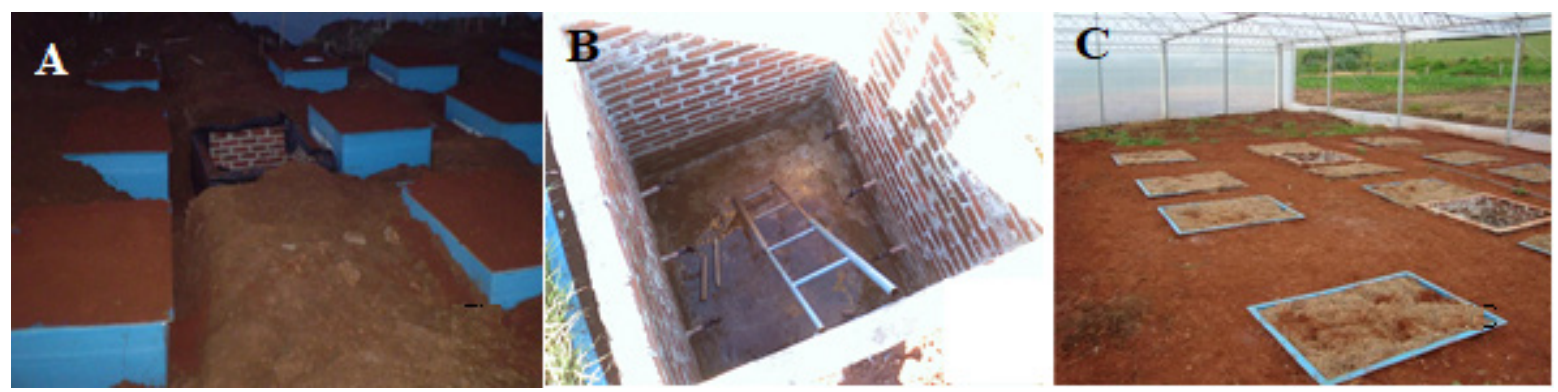

Os lisímetros, depois de nivelados, foram gradativamente preenchidos com solo, sendo que, inicialmente, receberam uma camada de $0,01 \mathrm{~m}$ de pedra brita $\mathrm{n}^{\circ}$ 2, para facilitar a drenagem de águas acumuladas externamente no fundo dos lisímetros. Em seguida, foi acondicionado o solo, em camadas, respeitando a ordem natural do mesmo de onde foi coletado. Para cada camada de 10 a $20 \mathrm{~cm}$ de solo colocado internamente, foi sendo depositado no entorno dos lisímetros, o solo do local onde estava sendo instalado o experimento, evitando-se assim pressões tanto para o interior com para o exterior desses (Figura 1A).

Os poços de observação foram construídos em alvenaria com tijolo maciço nas dimensões de 1,10 x 1,10 e $1,40 \mathrm{~m}$ de profundidade, nos quais foram conectados, individualmente, os lisímetros (Figura 1B). O fundo do poço foi concretado em desnível, com o objetivo de drenar os excessos de água que possam vir a existir.

$\mathrm{Na}$ sequência das ações, foi iniciada a construção de uma estrutura de metal de 10 x $16 \mathrm{~m}$ com 4,5 m de pé direito, com a finalidade de sustentar uma cobertura de PVC, para evitar a entrada de precipitações naturais nos lisímetros, uma vez que um dos objetivos da instalação dos lisímetros é o controle das lâminas de água aplicada e o controle da água lixiviada (Figura 1C).

O processo de umedecimento do solo foi realizado através da adição de água ao mesmo, com as torneiras dos canos de drenagem fechadas. Quando o solo apresentou uma lâmina de 0,02 $\mathrm{m}$ de água na superfície e não se observou mais a saída de bolhas de ar do interior do solo, as torneiras dos lisímetros foram abertas e a água de drenagem acondicionada em recipientes, onde no final da drenagem, 24 horas após a abertura das torneiras, segundo metodologia proposta por Bernardo et al. (2008), o solo foi considerado como tendo atingido a capacidade de campo.

Com o objetivo de restaurar a estrutura do solo e iniciar as definições da metodologia de coleta de água de drenagem, foi realizada a semeadura da cultura da aveia preta (Avena strigosa), não se utilizando neste momento qualquer tipo de correção de solo ou adubação.

\section{Teste de AVAliação da QUALIdAde da ÁGUa - Compostos Nitrogenados}

O experimento de lixiviação de compostos nitrogenados iniciou-se com a dessecação da aveia através da aplicação de 1 L.ha $^{-1}$ do produto Glifosato. Posteriormente, foram coletadas amostras de solo dos lisímetros na profundidade de 0 a $20 \mathrm{~cm}$ para análise da condição química do solo, os valores observados são aprestados no Quadro 1.

Quadro 1. Análise química do solo do interior dos lisímetros.

\begin{tabular}{|c|c|c|c|c|c|c|c|c|c|c|}
\hline \multicolumn{10}{|c|}{ IDENTIFICAÇÃO DA CONDIÇÃO QUÍMICA DO SOLO } \\
\hline PH & $\begin{array}{c}\text { Índice } \\
\text { SMP }\end{array}$ & $\begin{array}{c}\text { Argila } \\
\%\end{array}$ & $\begin{array}{c}\mathrm{M} . \mathrm{O} \\
\%\end{array}$ & $\begin{array}{c}\mathrm{K} \\
\mathrm{mg} . \mathrm{L}^{-1}\end{array}$ & $\begin{array}{c}\mathrm{P} \\
\mathrm{mg} \cdot \mathrm{L}^{-1}\end{array}$ & $\begin{array}{c}\mathrm{Ca} \\
\text { cmolc.L-1 }\end{array}$ & $\begin{array}{c}\mathrm{Mg} \\
\text { cmolc.L-1 }\end{array}$ & $\begin{array}{c}\mathrm{H}+\mathrm{AL} \\
\text { cmolc.L-1 }\end{array}$ & \multicolumn{2}{|c|}{$\begin{array}{c}\text { Sat. da } \\
\text { CTC }\end{array}$} \\
\hline 5,7 & 6,1 & 72 & 1,7 & 46 & 4,6 & 4,8 & 2,8 & 3,3 & 70,0 & 0,0 \\
\hline
\end{tabular}


Esses valores foram utilizados para a recomendação da adubação para a cultura do milho, segundo metodologia proposta pela Sociedade Brasileira de Ciências do Solo (2004), levando-se em consideração os três tratamentos, fontes de $\mathrm{N}$ (cama de aves, dejeto de suínos e nitrogênio mineral -ureia), para uma produtividade de grãos de $9000 \mathrm{~kg} / \mathrm{ha}^{-1}$ (Tabela 1). Além das três adubações, houve um tratamento testemunha sem nenhum tipo de adubação.

Tabela 1. Recomendação de adubação corretiva para cultura de milho para uma produtividade estimada de 9.000 $\mathrm{kg} / \mathrm{ha}^{-1}$, considerando 3 tratamentos.

\begin{tabular}{|c|c|c|c|}
\hline \multicolumn{4}{|c|}{ RECOMENDAÇÂO DE ADUBAÇÂO PARA CULTURA DO MILHO } \\
\hline \multirow{2}{*}{ NPK } & \multicolumn{3}{|c|}{ Necessidade para 9.000 kg.ha ${ }^{-1}$} \\
\hline & \multicolumn{3}{|c|}{ Quantidade aplicada - kg } \\
\hline ADUBO MINERAL & Ureia & SFT & $\mathrm{KCI}$ \\
\hline Adubação mineral base & 44,00 & 366,00 & 184,00 \\
\hline Adubação mineral cobertura & 323,00 & 0,00 & 0,00 \\
\hline Adubação mineral total & 367,00 & 366,00 & 184,00 \\
\hline ADUBO ORGÂNICO & \multicolumn{3}{|c|}{ Quantidade aplicada } \\
\hline Cama de aves & \multicolumn{3}{|c|}{$5137,00 \mathrm{~kg}$} \\
\hline Dejeto de suínos & \multicolumn{3}{|c|}{$52,50 \mathrm{~m}^{3}$} \\
\hline
\end{tabular}

Com base na recomendação, foram aplicados $5137 \mathrm{~kg} \cdot h \mathrm{ha}^{-1}$ de cama de aves, $52,5 \mathrm{~m}^{3} \mathrm{ha}^{-1}$ de dejeto de suínos e para adubação mineral (NPK) usou-se $44 \mathrm{~kg} \cdot \mathrm{ha}^{-1}$ de ureia na base e $323 \mathrm{~kg} \cdot \mathrm{ha}^{-1}$ em cobertura, $366 \mathrm{~kg} \cdot \mathrm{ha}^{-1} \mathrm{de}$ superfosfato triplo (SFT) e $184 \mathrm{~kg} \cdot \mathrm{ha}^{-1}$ de cloreto de potássio $(\mathrm{KCl})$ na base. A adubação orgânica com dejeto de suínos e cama de aves foi aplicada com regadores e a adubação mineral foi aplicada a lanço.

Para a semeadura da cultura do milho, utilizou-se a variedade AS 1551, sendo que a mesma foi semeada de forma manual, no sistema plantio direto, em linhas, com uma população de 60.000 plantas ha ${ }^{-1}$, com espaçamento entre linhas $45 \mathrm{~cm}$ e $6 \mathrm{~cm}$ de profundidade. A colheita da cultura ocorreu aos 143 dias após a emergência (DAE). O monitoramento da água drenada e da perda de nitrogênio foi realizado a partir da aplicação de $\mathrm{N}$ em présemeadura e prosseguiu com coletas a cada 30 dias até o dia 210, resultando em 8 coletas.

Devido ao fato do conjunto de lisímetros estarem protegidos de precipitações naturais, o suprimento de água às plantas foi fornecido via água de irrigação. As lâminas foram calculadas segundo a metodologia descrita por Pereira et al. (1997), que consideram a evapotranspiração como fator para aplicação de água via irrigação. Os dados meteorológicos, utilizados para compor as informações necessárias para a estimativa da evapotranspiração e consequentemente a lâmina de irrigação necessária, foram obtidos da estação meteorológica do Instituto Nacional de Meteorologia (INMET), instalada no campus de Frederico Westphalen. A lâmina de irrigação estimada foi aplicada por meio de regadores.

A coleta da água drenada dos lisímetros foi realizada nos poços de observação onde foram colocados recipientes de PVC de 20 litros. O volume total drenado foi medido e deste foi coletada uma amostra de $100 \mathrm{~mL}$ para a determinação da concentração de $\mathrm{N}$, sendo os valores observados apresentados na tabela 2 .

A água de drenagem coletada foi submetida a análise do teor de nitrogênio total, seguindo a metodologia indicada por Tedesco et al. (1995), utilizando liga Devarda e óxido de magnésio para determinação dos elementos nitrogenados e destilador de arraste de vapor semimicro Kjeldahl, para a destilação das amostras de água. As avaliações foram realizadas no laboratório de Pesquisa e Análise Química (LAPAQ), localizado nas dependências do campus da UFSM Frederico Westphalen.

Os valores obtidos nas análises da água foram comparados aos valores de limite máximo de resíduos (LMR), onde o LMR é a quantidade máxima de resíduo de uma substância que pode estar legalmente presente nos alimentos ou rações animais sem causar danos à saúde do consumidor (Jardim e Caldas 2009). O nível crítico 
utilizado como padrão foi a concentração permitida na água para consumo segundo a resolução do Conselho Nacional do Meio Ambiente - CONAMA n 357 (Brasil 2005).

As análises estatísticas foram analisadas no Software Genes, utilizando-se o teste estatístico de Tukey a 5\% de probabilidade de erro, para a comparação das médias obtidas entre as diferentes fontes de nitrogênio.

\section{Avaliação da contaminação do solo por Cu E ZN}

O experimento para avaliação da contaminação no solo por metais pesados ocorreu no ano de 2014. Nos lisímetros foram conduzidos três cultivos anteriores, sendo dois de milho e um de aveia e nesses foram aplicados as doses recomendadas de NPK para cada tratamento mencionado (dejeto de suínos, cama de aviário e adubação mineral). A coleta do solo foi realizada antecedendo o plantio do quarto cultivo, sendo este de aveia preta (Avena strigosa).

As amostras de solo foram coletadas em três pontos de cada lisímetro, sendo que em cada ponto foram coletadas amostras em 4 profundidades, sendo elas de 0-10, 10-20, 20-30 e 30-40 cm. Depois de coletadas, as amostras de solo foram secas em estufa de circulação forçada de ar sob temperatura de $60{ }^{\circ} \mathrm{C}$ por 24 horas e posteriormente moídas em cadinho de porcelana para a realização das análises em laboratório.

As análises dos metais presentes no solo foram realizadas no Laboratório de Análise e Pesquisas Químicas (LAPAQ) no campus da UFSM Frederico Westphalen, por meio de um Espectrômetro de Fluorescência de Raios-X por Energia Dispersiva, do modelo Shimadzu EDX-720. O método analítico usado foi o dos Parâmetros Fundamentais (PF) segundo Wastowski et al. (2010). Este método permite a obtenção da curva de sensibilidade do equipamento para cada elemento de interesse.

Para as análises foram utilizados $0,5 \mathrm{~g}$ de solo, acondicionados sob um filme de Mylar ${ }^{\circledR}$ de $2,5 \mu \mathrm{m}$ de espessura, esticado no fundo de uma cela de polietileno. Foram quantificados todos os elementos presentes no solo e para este estudo avaliados apenas o teor dos metais $\mathrm{Cu}$ e $\mathrm{Zn}$.

\section{Resultados e Discussão}

Avaliação dos compostos nitrogenados na água

$\mathrm{Na}$ tabela 2 são apresentados os valores de concentração de elementos nitrogenados, amônia $\left(\mathrm{N}^{-} \mathrm{NH}_{3}^{+}\right)$, nitrato + nitrito $\left(\mathrm{N}^{-\mathrm{NO}_{3}-} \mathrm{N}^{-\mathrm{NO}_{2}}\right)^{-}$e nitrogênio total (N-total), usados como fonte de adubação e que foram lixiviados e drenados para fora do perfil do solo nos lisímetros de drenagem. Pode-se observar que, nas oito coletas e para todas as fontes de nitrogênio, houve lixiviação de elementos nitrogenados. Pela análise da tabela 2, pode-se ainda inferir que, através da água coletada nos poços de observação, é possível avaliar a água lixiviada em cada lisímetro de drenagem e determinar os níveis dos elementos nitrogenados presentes na mesma. A adubação orgânica, principalmente com dejetos de suínos, possui uma série de elementos químicos prontamente disponíveis, ou que, depois de adicionados ao solo, acabam promovendo a mineralização dos elementos que poderão ser absorvidos pelas plantas da mesma forma que os fertilizantes minerais (Smanhotto et al. 2010). Por outro lado, o excesso ou a não absorção pelas plantas pode levar à lixiviação desses elementos. 


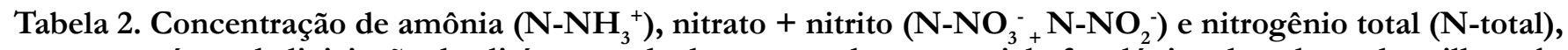
presente na água de lixiviação dos lisímetros de drenagem, durante o ciclo fenológico da cultura do milho sobre diferentes fontes de nitrogênio: cama de aves, dejeto de suínos ( $\mathrm{N}$ orgânico) e ureia ( $\mathrm{N}$ mineral) (adaptado de Rosa et al. 2018). DAS = dias após a semeadura.

\begin{tabular}{|c|c|c|c|c|c|c|}
\hline \multirow[b]{3}{*}{ DAS } & \multicolumn{4}{|c|}{$\mathrm{N}$ orgânico } & \multicolumn{2}{|c|}{$\mathrm{N}$ mineral } \\
\hline & \multirow{2}{*}{\multicolumn{2}{|c|}{ Cama de Aves }} & \multicolumn{2}{|c|}{ Dejeto de Suínos } & \multicolumn{2}{|c|}{ Ureia } \\
\hline & \multicolumn{5}{|c|}{ Amônia $\left(\mathrm{NH}_{3}^{+}\right)-$mg. $\mathrm{L}^{-1}$} & \\
\hline 0 & 0.313 & A & 0.3533 & A & 0.3300 & A \\
\hline 30 & 2.900 & A & 2.1000 & $A B$ & 1.8333 & B \\
\hline 60 & 3.066 & B & 4.8333 & A & 4.2333 & A \\
\hline 90 & 2.600 & B & 6.1000 & A & 5.5333 & A \\
\hline 120 & 2.166 & B & 4.2000 & A & 4.6000 & A \\
\hline 150 & 1.700 & B & 2.5000 & B & 3.5333 & A \\
\hline 180 & 1.366 & A & 1.8667 & A & 2.0333 & A \\
\hline 210 & 1.096 & $\mathrm{~A}$ & 1.0133 & $\mathrm{~A}$ & 0.6267 & A \\
\hline \multicolumn{7}{|c|}{ Nitrito + Nitrato $\left(\mathrm{NO}_{3}^{-}+\mathrm{NO}_{2}^{-}\right)-\mathrm{mg} \cdot \mathrm{L}^{-1}$} \\
\hline 0 & 0.0900 & A & 0.1367 & $\mathrm{~A}$ & 0.1033 & A \\
\hline 30 & 0.4667 & B & 1.6333 & A & 1.7000 & A \\
\hline 60 & 3.0333 & B & 4.4333 & A & 1.8000 & $\mathrm{C}$ \\
\hline 90 & 2.5667 & A & 3.2333 & A & 2.6000 & A \\
\hline 120 & 3.7333 & A & 3.0333 & A & 2.1000 & B \\
\hline 150 & 1.8667 & B & 2.7333 & A & 2.1767 & $\mathrm{AB}$ \\
\hline 180 & 1.6667 & A & 2.1333 & A & 1.8333 & A \\
\hline 210 & 1.4100 & A & 1.1800 & A & 0.6867 & A \\
\hline \multicolumn{7}{|c|}{ N-Total - mg.L $\mathrm{L}^{-1}$} \\
\hline 0 & 0.4033 & A & 0.4900 & A & 0.4333 & A \\
\hline 30 & 3.3667 & A & 3.7333 & A & 3.5333 & A \\
\hline 60 & 5.633 & $\mathrm{C}$ & 9.2667 & A & 6.0333 & B \\
\hline 90 & 6.0667 & B & 9.3333 & A & 8.1333 & A \\
\hline 120 & 5.9000 & A & 7.2333 & A & 6.7000 & A \\
\hline 150 & 3.5667 & B & 5.2333 & $\mathrm{C}$ & 5.7100 & A \\
\hline 180 & 3.0333 & A & 4.0000 & A & 3.8667 & A \\
\hline 210 & 2.5067 & A & 2.1933 & A & 1.4267 & B \\
\hline
\end{tabular}

*Médias seguidas pelas mesmas letras na linha não diferem estatisticamente entre si, pelo teste de Tukey a 5\% de probabilidade de erro.

Observou-se diferença significativa entre os dias de coletas 30, 60 e 150 DAS, para a concentração de nitrato + nitrito presente na água lixiviada entre os tratamentos com $\mathrm{N}$ orgânico (cama de aves e dejeto de suínos). O tratamento com dejeto de suínos apresentou aos 60 DAS a maior concentração de nitrato + nitrito. Entretanto, verificou-se que a maior concentração de nitrato + nitrito no tratamento com ureia ocorreu aos 90 DAS. Deferindo dos resultados observados nos estudos realizados por Aita et al. (2007), que indicaram que o $\mathrm{N}$ amoniacal presente em dejetos líquidos de suínos foi rapidamente nitrificado no solo sob sistema de plantio direto sendo esse nitrificado entre 15 a 20 dias após a sua aplicação.

Durante o monitoramento da água lixiviada, as concentrações de $\mathrm{N}$-total (Tabela 2) foram superiores ao limite de 2,18 mg. $\mathrm{L}^{-1}$, definido para ambientes lóticos (LMR) de acordo com a Resolução no 357 do CONAMA (Brasil 2005), em todas as datas de coleta após aplicação dos tratamentos, e para todos os tratamentos, com exceção da data de coleta de 210 DAS no tratamento que utilizou-se a fonte de $\mathrm{N}$ inorgânico (ureia). Esse resultado demonstra que todas as fontes de $\mathrm{N}$ utilizadas são potencialmente poluidoras da água. Entretanto, evidenciou-se que a estrutura de lisímetros se mostrou eficiente para a coleta de dados e posterior avaliação da contaminação das águas sub superficiais.

Aplicações sucessivas de adubações podem aumentar o risco de contaminação por nitrato em águas subterrâneas, pois este permanece na solução do solo, favorecendo sua lixiviação no perfil para profundidades inexploradas pelas raízes (Santos et al. 2015). Segundo Fioreze et al. (2012), a classe textural também afeta a 
lixiviação do $\mathrm{N}$ no solo após a adição de adubos orgânicos, sendo que solos muito argilosos retardam este processo, reduzindo assim o potencial de lixiviação em relação aos solos arenosos.

Um dos grandes problemas deste processo, é que concentrações maiores que $10 \mathrm{mg} . \mathrm{L}^{-1}$ de nitrato (Brasil 2005) podem ser fatais para crianças com idade inferior há seis meses, além de causar problemas na saúde dos animais. Segundo Biguelini e Gumy (2012), o nitrato é convertido a nitrito, que se combina com a hemoglobina no sangue, formando metamoglobina, e causando em crianças a "síndrome do bebê azul", além de outros problemas que podem ser causados pela formação de nitrosaminas cancerígenas.

O nitrato apresenta alta solubilidade e fraca adsorção com as partículas do solo, devido a isso, acompanha o movimento da água, ou seja, o nitrato se move no sentido descendente em condições de excessiva precipitação e irrigação, e no sentido ascendente, por capilaridade, em períodos de seca (Muchovej e Rechcigl 1994). A alta mobilidade do nitrato no solo, associada ao risco de contaminação do lençol freático justifica a preocupação em relação à disposição de efluentes ricos em nitrogênio no solo (Silva et al. 2017) e justifica assim, a utilização de métodos de mensuração das quantidades ideais de uso de fertilizantes, reduzindo os impactos da lixiviação de elementos nitrogenados, e visando o uso sustentável na produção de alimentos, tanto de produção agrícola como de proteína animal.

\section{Avaliação da contaminação do solo por Cu e Zn}

Nas Figuras 2 estão contidos os resultados das concentrações de $\mathrm{Cu}$ e $\mathrm{Zn}\left(\mathrm{mg} \cdot \mathrm{kg}^{-1}\right.$ ) no solo, em função das profundidades amostradas de 0-10, 10-20, 20-30 e 30-40 cm, em solo adubado com dejeto de suínos, cama de aves e adubação mineral.

Figura 2. A) Concentração de zinco $(\mathrm{Zn})$ e B) Concentração de cobre $(\mathrm{Cu})$ em diferentes profundidades de solos adubados com dejeto de suínos, cama de aves e adubo químico NPK. Adaptado de Da Rosa et al. (2018).
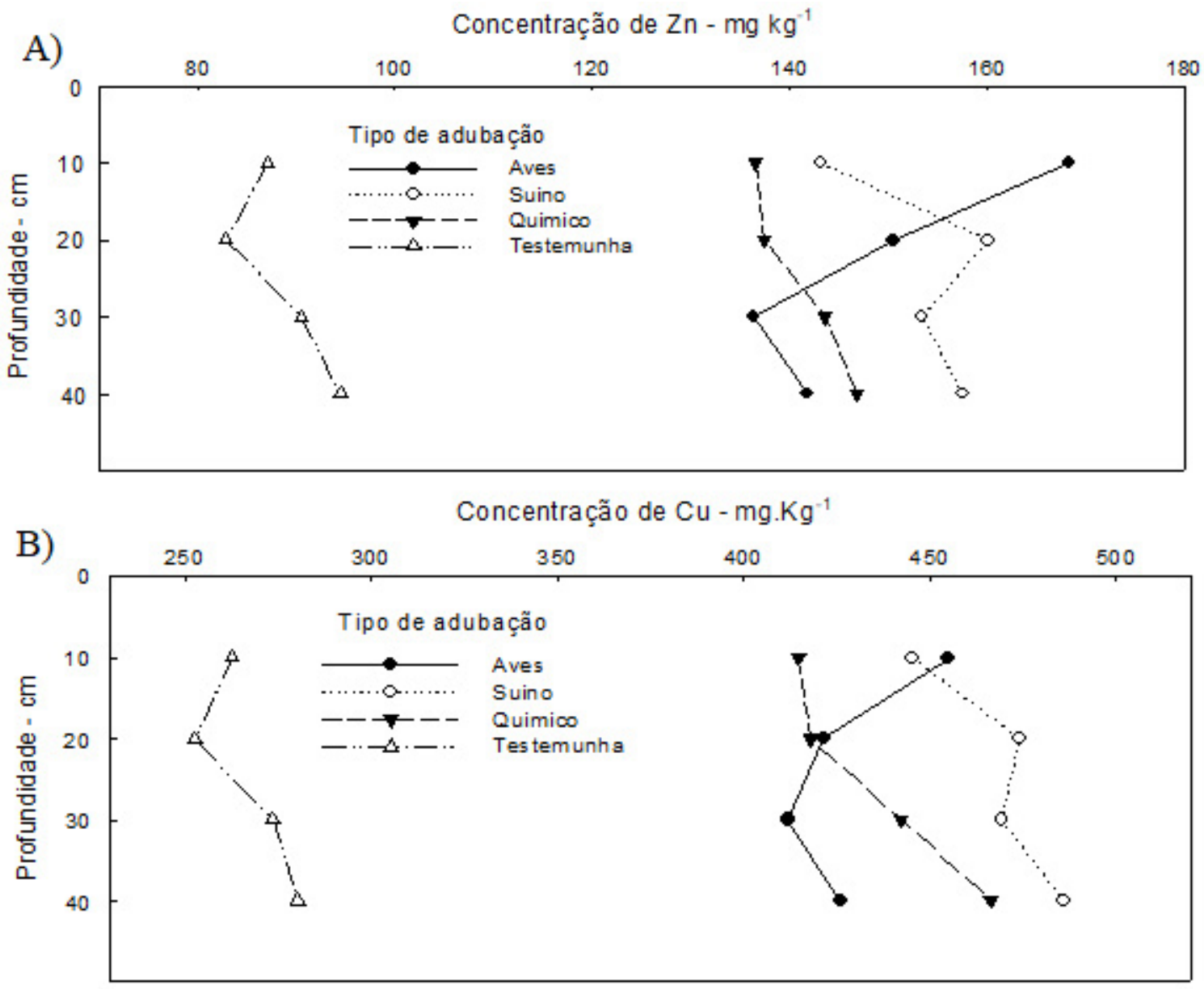
É possível constatar pela Figura 2 que o metal Zn presente na adubação ficou acumulado no perfil do solo, quando comparado com o perfil do solo testemunha (Da Rosa et al. 2018). Esses resultados corroboram com os obtidos por Basso et al. (2012) em áreas de lavoura e pastagem onde houve a aplicação de dejetos de suíno. $\mathrm{Da}$ mesma forma, houve tendência de acumulação de $\mathrm{Cu}$ em todos os tratamentos, quando comparados ao tratamento testemunha.

Os lisímetros com os solos adubados com dejeto de suínos e adubação mineral, apresentaram maior acúmulo de $\mathrm{Cu}$ na camada de 30-40 cm de profundidade com 476,24 e 481,03 mg.kg-1, respectivamente, enquanto que solos adubados com cama de aves a maior concentração foi observada na superfície $(0-10 \mathrm{~cm}) \mathrm{com} 455 \mathrm{mg} \cdot \mathrm{kg}^{-1}$.

$\mathrm{O}$ acúmulo de $\mathrm{Cu}$ e $\mathrm{Zn}$ no solo, oriundos da adubação tanto orgânica quanto mineral, resultou na contaminação do solo por esses metais, os quais, ao se acumularem em altas concentrações no solo, podem se movimentar no perfil e atingir camadas mais profundas. No entanto, segundo Scherer et al. (2010), em solos argilosos esses nutrientes se acumulam principalmente na camada superficial, Observa-se ainda, que além do acúmulo desses metais, há a mobilidade em direção às camadas mais profundas do perfil do solo. A mobilidade dos metais é determinada pelos atributos do solo, tais como teores e tipos de argila, $\mathrm{pH}$, capacidade de troca de cátions e teor de matéria orgânica que influenciam nas reações de adsorção, precipitação/dissolução, complexação e oxirredução (Paganini et al. 2004).

\section{ConClusão}

A metodologia aplicada para a instalação do conjunto de lisímetros de drenagem possibilitou a avaliação da lixiviação de nitrato de diferentes origens e a quantificação dos elementos nitrogenados gerados.

A utilização de lisímetros de drenagem permitiu a avaliação, ao longo do tempo, da contaminação do solo por cobre e zinco, presentes na composição de diferentes tipos de adubações orgânicas e minerais.

Os lisímetros de drenagem se mostraram eficazes para os estudos do impacto dos efluentes e adições químicas ao solo e seu reflexo nas águas lixiviadas, tendo como vantagens o manuseio seguro desses efluentes e contaminações desnecessárias em ambientes de pesquisa. Além disso, essa técnica pode ser destinada à avaliação de outros tipos de efluentes.

\section{Agradecimentos}

Os autores agradecem a todos aqueles que direta e indiretamente contribuíram para execução deste trabalho, em especial, aos integrantes do Grupo de Pesquisa Gerenciamento Ambiental e Manejo de Recursos Hídricos (GAMRH).

\section{REFERÊNCIAS}

Aita C, Giacomini SJ, Hübner AP. 2007. Nitrificação do nitrogênio amoniacal de dejetos líquidos de suínos em solo sob sistema de plantio direto. Pesquisa Agropecuária Brasileira, 42(1):95-102. DOI 10.1590/S0100-204X2007000100013

Basso CJ et al. 2012. Teores totais de metais pesados no solo após aplicação de dejeto líquido de suínos. Ciência Rural, 42(4):653-659. DOI: 10.1590/S0103-84782012000400012

Bernardo S, Soares AA, Mantovani EC. 2008. Manual de irrigação, 8ed., Viçosa: UFV, 625p. 
Biguelini CP, Gumy MP. 2012. Saúde Ambiental: índices de nitrato em águas subterrâneas de poços profundos na região sudoeste do Paraná. Faz Ciência (Brasil), 14(20): 153-175.

Brasil. Conselho Nacional do Meio Ambiente - CONAMA. 2005. Resolução no 357. Brasília, DF. 27 p.

Carvalho NL, Zabot V. 2012. Nitrogênio: Nutriente ou Poluente? Revista Eletrônica em Gestão, Educação e Tecnologia Ambiental, 6(6):960-974. DOI http://dx.doi.org/10.5902/223611704671

Da Rosa GM, Gabriel M, Wastowski AD, Da rosa RS. 2018. Behavior of copper and zinc metals in soil profile, submitted to different sources of fertilization. Environmental Quality Management (PRINT), 28:01-05. DOI: https://doi.org/10.1002/ tqem. 21574

De Mera CMP, Lorenzini R, Wollmann MR. 2011. Percepção com suinocultores de Tapera/RS sobre o uso de dejetos suínos na lavoura e o impacto ambiental. Extensão Rural, (21):77-100.

Fioreze C et al. 2012. Liberação do N em solos de diferentes texturas com ou sem adubos orgânicos. Ciência Rural, 42(7):1187-1192. DOI: 10.1590/S0103-84782012005000045

Hong $\mathrm{N}$ et al. 2007. Economically optimal nitrogen rate reduces soil residual nitrate. Journal of environmental quality, 36(2):354-362. DOI:10.2134 / jeq2006.0173

Jardim ANO, Caldas ED. 2009. Exposição humana a substâncias químicas potencialmente tóxicas na dieta e os riscos para saúde. Química Nova, 32(7):1898-1909. DOI: http://dx.doi.org/10.1590/S0100-40422009000700036

Muchovej RMC, Rechcigl JE. 1994. Impact of Nitrogen Fertilization of Pastures and Turfgrasses on Water Quality. In: Soil processes and water quality. Lewis Publication. Boca Raton, p. 91-135.

Oliveira PAV. 2004. Tecnologias para o manejo de resíduos na produção de suínos: manual de boas práticas. 1ed., Concórdia: Embrapa Suínos e Aves. 129 p.

Paganini WS, Souza A de, Bocchiglieri MM. 2004. Avaliação do comportamento de metais pesados no tratamento de esgotos por disposição no solo. Engenharia Sanitária e Ambiental, Rio de Janeiro, 9(3): 225-239. DOI: 10.1590/S141341522004000300009

Pereira AR, Nova NAV, Sediyama GC. 1997. Evapo(transpi)ração. Piracicaba: Fealq. 183p.

Rosa GM da, Silva JC, Gabriel M, Mendonça AM, Costa Junior JA, Wastowski AD. 2018. Leaching of the different forms of nitrogen by the application of poultry litter, swine waste, and mineral nitrogen on corn cultures (L.). Environmental Quality Management (PRINT), 28:01-08. DOI: https://doi.org/10.1002/tqem.21586

Santos SCG, Menezes SJFS, Benites VM. 2015. Lixiviação de nitrogênio em um Latossolo Vermelho cultivado com soja após aplicação de dejetos líquidos de suínos. Global Science and Technology, 8(2):49-60.

Scherer EE, Esi CN, Massotti Z. 2010. Atributos químicos do solo influenciados por sucessivas aplicações de dejetos suínos em áreas agrícolas de Santa Catarina. Revista Brasileira de Ciência do Solo, 34(4):1375-1384. DOI: 10.1590/ S010006832010000400034 
Silva JBG et al. 2017. Mobilidade dos íons nitrato e amônio em área agrícola sob adubação com água residuária de bovinocultura de leite e torta de mamona. Revista Engenharia na Agricultura. 25(3): 200-211. DOI: https://doi. org/10.13083/reveng.v25i3.678

Smanhotto A et al. 2010. Cobre e zinco no material percolado e no solo com a aplicação de água residuária de suinocultura em solo cultivado com soja. Engenharia Agrícola (Brasil) 30(2): 346-357.

Sociedade brasileira de ciências do solo. Comissão de química e fertilidade do solo. 2004. Manual de Adubação e de Calagem para os Estados do Rio Grande do Sul e Santa Catarina. Porto Alegre, RS. 401p.

Streck EV et al. 2008 Solos do Rio Grande do Sul. Porto Alegre: UFRGS: EMATER/RS-ASCAR.

Tedesco MJ et al. 1995. Análise de solo, plantas e outros materiais. Porto Alegre, Departamento de Solos: UFRGS. 174 p.

Wastowski $\mathrm{AD}$ et al. 2010. Caracterização dos níveis de elementos químicos em solo, submetido a diferentes sistemas de uso e manejo, utilizando Espectrometria de Fluorescência de Raios-X por Energia Dispersiva (EDXRF). Química Nova, 33(7): 1449-1452. DOI: 10.1590/S010040422010000700005. 